\title{
Sleep disturbances in highly stress reactive mice: Modeling endophenotypes of major depression
}

\author{
Thomas Fenzl ${ }^{1 * \dagger}{ }^{*}$, Chadi Touma ${ }^{1 \dagger}$, Christoph PN Romanowskil, Jörg Ruschel ${ }^{2}$, Florian Holsboer ${ }^{1}$, Rainer Landgraf ${ }^{1}$, \\ Mayumi Kimura', Alexander Yassouridis ${ }^{1}$
}

\begin{abstract}
Background: Neuronal mechanisms underlying affective disorders such as major depression (MD) are still poorly understood. By selectively breeding mice for high (HR), intermediate (IR), or low (LR) reactivity of the hypothalamicpituitary-adrenocortical (HPA) axis, we recently established a new genetic animal model of extremes in stress reactivity (SR). Studies characterizing this SR mouse model on the behavioral, endocrine, and neurobiological levels revealed several similarities with key endophenotypes observed in MD patients. HR mice were shown to have changes in rhythmicity and sleep measures such as rapid eye movement sleep (REMS) and non-REM sleep (NREMS) as well as in slow wave activity, indicative of reduced sleep efficacy and increased REMS. In the present study we were interested in how far a detailed spectral analysis of several electroencephalogram (EEG) parameters, including relevant frequency bands, could reveal further alterations of sleep architecture in this animal model. Eight adult males of each of the three breeding lines were equipped with epidural EEG and intramuscular electromyogram (EMG) electrodes. After recovery, EEG and EMG recordings were performed for two days.
\end{abstract}

Results: Differences in the amount of REMS and wakefulness and in the number of transitions between vigilance states were found in HR mice, when compared with IR and LR animals. Increased frequencies of transitions from NREMS to REMS and from REMS to wakefulness in HR animals were robust across the light-dark cycle. Detailed statistical analyses of spectral EEG parameters showed that especially during NREMS the power of the theta $(6-9 \mathrm{~Hz})$, alpha $(10-15 \mathrm{~Hz})$ and eta $(16-22.75 \mathrm{~Hz})$ bands was significantly different between the three breeding lines. Well defined distributions of significant power differences could be assigned to different times during the light and the dark phase. Especially during NREMS, group differences were robust and could be continuously monitored across the light-dark cycle.

Conclusions: The HR mice, i.e. those animals that have a genetic predisposition to hyper-activating their HPA axis in response to stressors, showed disturbed patterns in sleep architecture, similar to what is known from depressed patients. Significant alterations in several frequency bands of the EEG, which also seem to at least partly mimic clinical observations, suggest the SR mouse lines as a promising animal model for basic research of mechanisms underlying sleep impairments in MD.

\section{Background}

As an adaptation to the regular day/night cycles, organisms synchronize their physical activities, energy metabolism, immune functions and sleep by means of a circadian clock system [1-3]. In addition, individuals continuously face unforeseen short- and long-term changes in the environment called "stressors", which

\footnotetext{
* Correspondence: tomf@mpipsykl.mpg.de

+ Contributed equally

'Max-Planck-Institute of Psychiatry, Kraepelinstrasse 2, 80804 Munich, Germany

Full list of author information is available at the end of the article
}

can be physical or psychological $[4,5]$. To adapt to these stressful stimuli, another regulatory system, the stress system, has evolved which senses environmental changes through various sensory organs, processes them in the central nervous system (CNS) and adjusts the CNS and peripheral organ activities to improve chances for survival in nature [6-8]. The major system regulating internal homeostasis is the hypothalamic-pituitary-adrenal (HPA) axis, which accounts for circadian activity and mediates the adaptive response to stressors (see reviews cited above).

\section{Biomed Central}

(c) 2011 Fenzl et al; licensee BioMed Central Ltd. This is an Open Access article distributed under the terms of the Creative Commons Attribution License (http://creativecommons.org/licenses/by/2.0), which permits unrestricted use, distribution, and reproduction in any medium, provided the original work is properly cited. 
The clock and the stress system are both fundamental for survival and thus communicate with one another at multiple levels to adjust numerous physiological activities [1,9-11]. Importantly, dysregulation in either of these systems can lead to similar pathologic conditions, including sleep-related problems and mood disorders such as major depression (MD) [10,12-14].

Therefore, it is not surprising that sleep disturbances are among the most common symptoms of MD and characteristic sleep electroencephalographic (EEG) alterations are one of the most robust predictors of an emergent depressive episode [13,15-17]. Compared to healthy subjects, EEG recordings, which allow to objectively assessing sleep structure alterations, revealed that MD patients often suffer from insomnia and sleep fragmentation. They also show a reduced latency to the first episode of REMS, an increased proportion of REMS (increased REMS density) and reduced slow-wave activity (SWA) during NREMS $[12,13,16,18]$. Most changes of the sleep EEG pattern prevalent during a depressive episode are moderated or even disappear following successful treatment. Those patients where these sleep EEG abnormalities persist, despite their full clinical remission are at increased risk for relapse into another disease episode [19-21]. Furthermore, healthy high-risk probands with a positive family history of affective disorders also have been found to show an increased REM density, indicating that some of the sleep EEG changes might represent neurobiological vulnerability markers or endophenotypes of the disease [22,23].

Another biological hallmark of MD is a dysregulation of the HPA axis (hyper- or hypo-activity), largely involving pathological alterations in the corticotrophinreleasing hormone (CRH) system [6,13,17,24-27]. Common neuroendocrine symptoms of severely depressed patients include a flattened diurnal rhythm of glucocorticoid (GC) secretion, elevated plasma GC concentrations (hypercortisolism) and adrenal hyperplasia [28-31]. Furthermore, dysfunctional GC receptormediated negative feedback regulation of the HPA axis and changes in vasopressin and $\mathrm{CRH}$ responsiveness have frequently been described (see reviews cited above). However, it is increasingly acknowledged that the diagnosis of MD encompasses patients, who do not necessarily share the same disease biology, supporting the concept that depression needs to be differentiated accordingly to different causal mechanisms $[13,25$, $26,32,33]$. For instance, HPA axis overdrive, related to an enhanced secretion of $\mathrm{CRH}$ and an impaired negative feedback via GC receptors, is most consistently observed in patients with psychotic depression. These patients also show the most pronounced sleep-EEG alterations, including disrupted sleep, decreased SWA and short REMS latency. In contrast, patients suffering from the so-called atypical subtype of depression are characterised by markedly reduced activity of the HPA axis, while sleep-EEG data suggest that SWA is not reduced and REMS parameters are not considerably altered in these patients $[13,32]$.

Based on the vital link between stress sensitivity and the development of MD $[6,17,24,27,34]$, a new genetic animal model has recently been established, focusing on alterations in HPA axis reactivity as one of the major endophenotypes in depressed patients [35]. This so-called 'stress reactivity' (SR) mouse model consists of three separate breeding lines selected for either high (HR), intermediate (IR), or low (LR) corticosterone increase in response to a moderate psychological stressor (15-min restraint). Significant differences in the reactivity of the HPA axis between HR, IR (independent "control"-line) and LR mice were already found in the first generation of the selective breeding process and proved to be a highly heritable trait, i.e. the respective phenotype was confirmed across all subsequent generations and could even be increased by assortative breeding [35]. Moreover, results of an extensive behavioral test battery applied to the selected mouse lines as well as neuroendocrine characterisation experiments revealed several phenotypic similarities with changes observed in depressive patients [35-38]. In general, HR animals showed cognitive deficits, particularly in hippocampusdependent tasks, and were relatively hyperactive in some behavioral paradigms, resembling symptoms of restlessness and agitation often seen in psychotic and melancholic depression $[35,36,38]$. LR mice, on the other hand, showed clearly more passive coping styles, corresponding to signs of retardation and retreat observed in atypical depression [35]. Furthermore, we found that hyper-responsiveness to stressors was associated with rhythmicity changes (increased physical activity towards the end of the resting period), resembling symptoms like restlessness, sleep continuity disturbances and early awakenings that are commonly seen in psychotic and melancholic MD patients [37]. Additionally, HR mice also showed neuroendocrine abnormalities similar to symptoms of MD patients such as reduced amplitude of the circadian GC rhythm and elevated trough levels [35,37]. Sleep-EEG analyses, furthermore, revealed changes in REMS and NREMS as well as SWA, indicative of reduced sleep efficacy and REMS disinhibition in HR mice [37].

Therefore, in the present study we were interested in how far a detailed spectral analysis of several frequency bands, including a sophisticated event history analysis [39], could reveal further alterations in the sleep architecture of this animal model of affective disorders. This is of particular interest, as such an in-depth analysis of sleep characteristics is often used in human MD patients 
(see references given above), but to our knowledge has not been applied to characterise sleep in a genetic animal model for extremes in HPA axis reactivity. Thus, our data can contribute to understanding the basic mechanisms underlying sleep disturbances associated with HPA axis dysfunctions and could ultimately be used to elucidate the pathophysiology of sleep impairments in MD patients, including the development of new treatment options for the disorder.

\section{Results}

The evaluation of individual vigilance states revealed a typical circadian distribution of the normed durations of WAKE, NREMS and REMS across the recording session in all three breeding lines (Figure 1). During the light periods L1 (ZT0-6) and L2 (ZT6-12), all animals spent more time in NREMS than in WAKE, while especially during the first half of the dark period D1 (ZT12-18) all animals were more awake. During L1, significant group differences were found for REMS among HR, LR and IR animals $\left(\mathrm{F}_{(2,20)}=9.535 ; \mathrm{p}=0.006\right)$. Post hoc tests revealed a significantly increased amount of REMS in HR mice, when compared with IR and LR animals (Bonferroni modified LSD-Tests, $\mathrm{p}<0.05)$. In L2, significant group effects were found for all three vigilance states, i.e. WAKE $\left(\mathrm{F}_{(2,20)}=6.108 ; \mathrm{p}=0.03\right)$, NREMS $\left(\mathrm{F}_{(2,20)}=\right.$ $6.108 ; \mathrm{p}=0.01)$ and $\operatorname{REMS}\left(\mathrm{F}_{(2,20)}=6.108 ; \mathrm{p}=0.008\right)$. Whereas for WAKE the significant group effects were caused only by the differences between HR and LR, for NREMS and REMS the group effects derived from significant differences among all three breeding lines (Bonferroni modified LSD-Tests, $\mathrm{p}<0.05)$. During D1, no differences in mean durations could be found between the groups. During D2, however, strong group differences were found for $\operatorname{REMS}\left(\mathrm{F}_{(2,20)}=5.573 ; \mathrm{p}=0.012\right)$.

As expected, the most transitions were found between WAKE and NREMS and vice versa (Figure 2, L1 - D2). The detailed analysis of the normed transition frequencies calculated for each breeding line revealed significant differences in L2 between REMS and WAKE $\left(\mathrm{F}_{(2,20)}=\right.$ 5.163; $\mathrm{p}=0.016$; HR vs. IR and LR) and in D1 between REMS and WAKE $\left(\mathrm{F}_{(2,20)}=4.316 ; \mathrm{p}=0.028\right)$. In

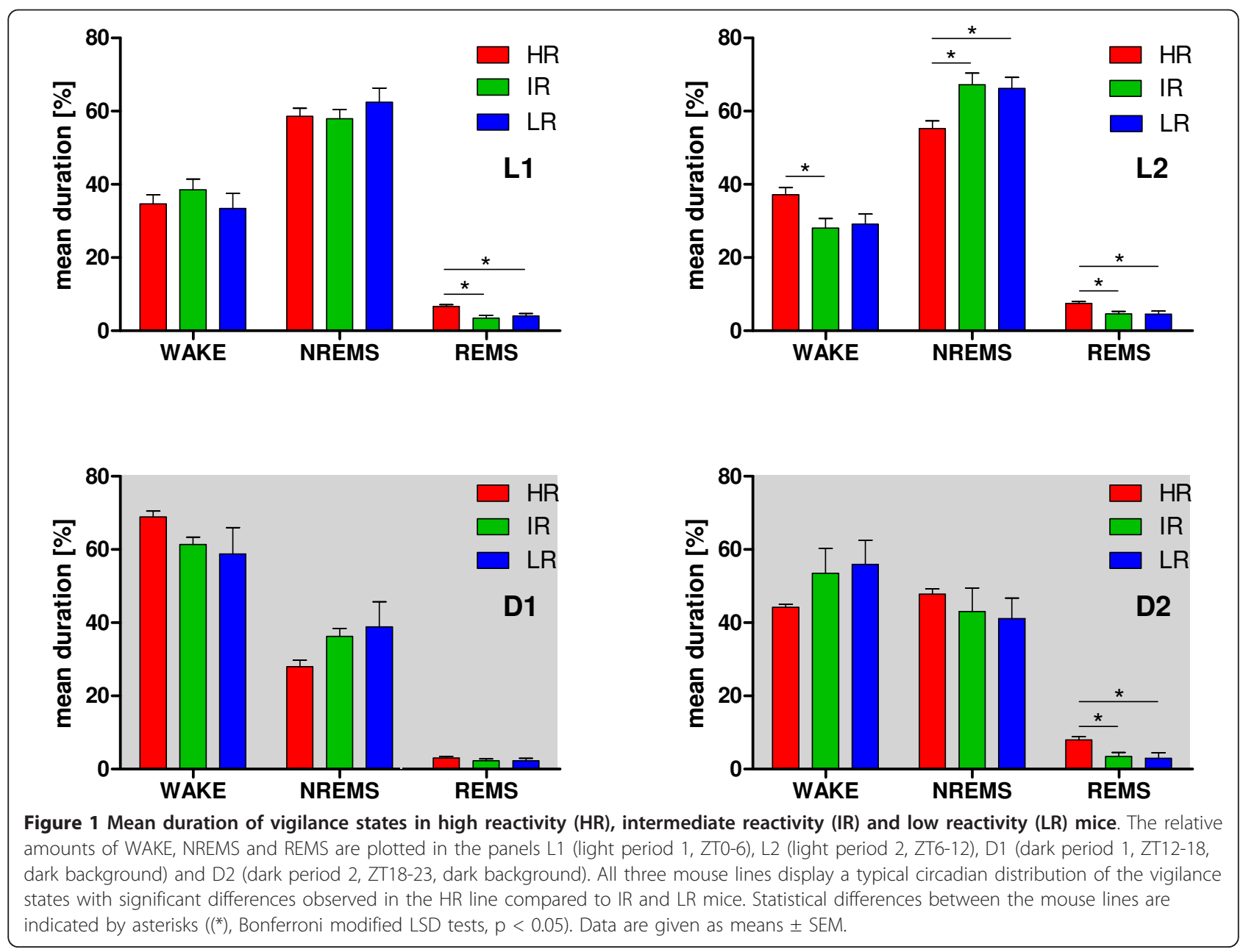




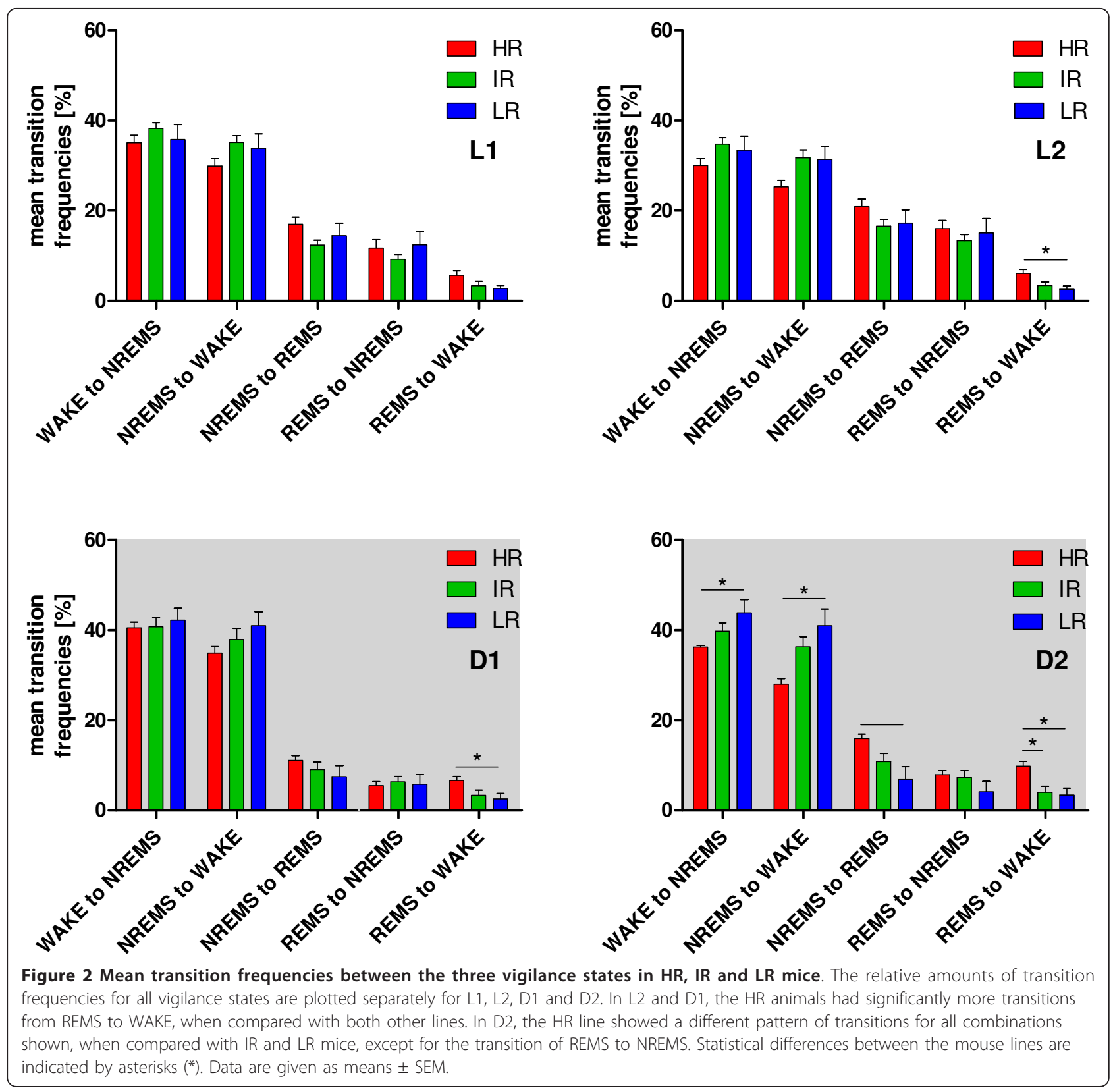

general, the fewest transitions were detected between REMS and WAKE (Figure 2, L1 - D2; HR vs. IR and LR). In the time interval D2 group comparisons revealed significant effects on the transition frequencies, which were considerable regarding NREMS to WAKE $\left(\mathrm{F}_{(2,20)}=\right.$ 6.632; $\mathrm{p}=0.006)$, REMS to WAKE $\left(\mathrm{F}_{(2,20)}=7.322 ; \mathrm{p}=\right.$ 0.004 ) and less pronounced regarding WAKE to NREMS $\left(\mathrm{F}_{(2,20)}=3.893 ; \mathrm{p}=0.037\right)$ and NREMS to $\operatorname{REMS}\left(\mathrm{F}_{(2,20)}=5.624 ; \mathrm{p}=0.012\right)$. These transitions showed significant differences preponderantly between HR and LR animals (Bonferroni modified LSD-Tests, $p<0.05)$. The increased duration of REMS in HR animals, shown in Figure 1 was not a consequence of an overall increased REMS episode length (Figure 3, for L1: $\mathrm{F}_{(2,20)}=1.339 ; \mathrm{p}=0.287$, for $\mathrm{L} 2: \mathrm{F}_{(2,20)}=0.173 ; \mathrm{p}=$ 0.843 , for $\mathrm{D} 1: \mathrm{F}_{(2,20)}=0.517 ; \mathrm{p}=0.605$ and for $\mathrm{D} 2$ : $\left.\mathrm{F}_{(2,20)}=0.518 ; \mathrm{p}=0.604\right)$ but rather due to an increased number of transitions from NREMS into REMS and back from REMS towards WAKE.

After addressing a stability hypothesis on continuity parameters (please refer to the methods section) for particular frequency bands in NREMS (Figure 4, left column), we found that the power of the theta $(6-9 \mathrm{~Hz})$ and alpha-band (10-15 Hz) in LR animals was stable and continuously below the corresponding powers of the other two breeding lines (Wilcoxon matched paired 


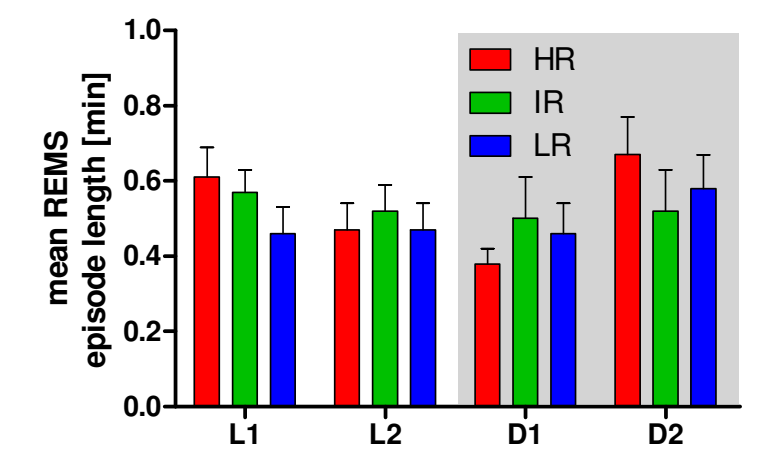

Figure 3 Mean REMS episode length in HR, IR and LR mice Group-comparisons for all three breeding lines during L1, L2, D1 and $D 2$ revealed no significant differences for the mean REMS episode length. Data are given as means \pm SEM.

test, $\mathrm{p}<0.05)$. At the eta-band $(16-22.75 \mathrm{~Hz})$, a stable differentiation could only be observed between HR and IR animals. For all other frequency bands, no continuously stable differentiations were found, neither in WAKE nor during REMS. After testing the stability on continuity parameters for particular transitions (Figure 4, right column), we found that the frequencies of transitions from NREMS to REMS and from REMS to WAKE in HR animals were stable and continuously above the corresponding transition frequencies of IR and LR (Wilcoxon matched paired test, $\mathrm{p}<0.05$ ). All other possible transitions revealed no significantly different continuity parameters.

Further, we were interested in the distribution of the power of delta $(0.75-5 \mathrm{~Hz})$-, theta-, alpha-, eta- and beta $(23-31.75 \mathrm{~Hz})$-frequency bands in all three breeding lines. Without differentiating between WAKE, NREMS and REMS, during L1 (Figure 5) the mean power of the alpha band revealed a significant group effect $\left(\mathrm{F}_{(10,32)}=3.94 ; \mathrm{p}=0.001\right)$, which was attributed to significant differences between HR and LR animals (Bonferroni modified LSD tests, $\mathrm{p}<0.05$ ). In L2, the power of the eta band significantly differed between all three groups $\left(\mathrm{F}_{(10,32)}=3.99 ; \mathrm{p}=0.001\right)$. Post-hoc Bonferroni tests revealed significant differences solely between HR and IR mice. Whereas in the first six hours of the dark period (D1), no significant differences in any of the considered power spectra appeared, with the power of the theta band within the second half of the dark period (D2) revealing significant distinctions between HR, LR and IR animals $\left(\mathrm{F}_{(10,32)}=3.15 ; \mathrm{p}=\right.$ 0.007). These differences were detected between HR and LR animals and between IR and LR mice (Bonferroni modified LSD tests, $\mathrm{p}<0.05$ ).

Additionally, we examined the distribution of the power of delta-, theta-, alpha-, eta- and beta-frequency bands determined in all three breeding lines separately for NREMS and REMS. When considering NREMS during L1, significant effects in several spectra were found between the groups $\left(\mathrm{F}_{(10,32)}=3.72 ; \mathrm{p}=0.002\right)$, which were attributed to clear group differences in the theta-, alpha- and eta-band (univariate F-tests in MANOVA). For the power of these bands, the HR and LR animals showed significant differences. Differences were also detected between IR and LR animals, but only for the power of the eta-band (Bonferroni modified LSD tests, $\mathrm{p}$ $<0.05)$. During L2, the power of the spectra in NREMS revealed also significant group differences $\left(F_{(10,32)}=\right.$ 4.22; $\mathrm{p}=0.001$ ), caused mostly by the significant differences between HR and LR in the theta-band and between IR and LR in the eta-band (Bonferroni modified LSD tests, $\mathrm{p}<0.05)$. During D1, differences could only be detected for the theta-band $\left(\mathrm{F}_{(10,32)}=3.56\right.$; $\mathrm{p}=$ 0.003 ) between HR and LR mice (Bonferroni corrected). Finally, during D2 group comparisons revealed also a significant effect on the spectral powers $\left(\mathrm{F}_{(10.32)}=4.57\right.$; $\mathrm{p}<0.001$ ), which was profound regarding the power of the theta and alpha bands (univariate F tests in MANOVA, $\mathrm{p}<0.05$ ). The changes in these power spectra were caused by the distinctions between HR and LR for the theta-band and between HR and LR for the alphaband (Bonferroni modified LSD tests, $\mathrm{p}<0.05$ ). When considering all power spectra separately during REMS, we did not find any significant group differences throughout all four time periods L1-D2.

\section{Discussion}

The stress reactivity (SR) mouse model was established as a new mouse model for affective disorders comprising neuroendocrine core symptoms such as a hyperreactive HPA axis, frequently observed in depressed patients [35]. In the present study, we provide evidence supporting the establishment of the SR model as a promising animal model of major depression, especially when the attention is drawn towards disturbed sleep as one of the clinical hallmarks in major depression.

\section{General sleep/wake behavior}

Our experiments showed that all three breeding lines of the SR model, namely the HR, IR and LR line have a typical distribution of sleep and wakefulness across the light/dark cycle with increased amounts of sleep during the light period and of wakefulness and activity during the dark period (Figure 1). This typical sleep/wake pattern was shown for mice in numerous studies. To our knowledge, one of the first studies which investigated this behavior systematically in several nocturnal rodents showed that the sleep time in Mus musculus was distributed differentially during the two phases of the light cycle, with more sleep during the light than during the dark phase [40]. 

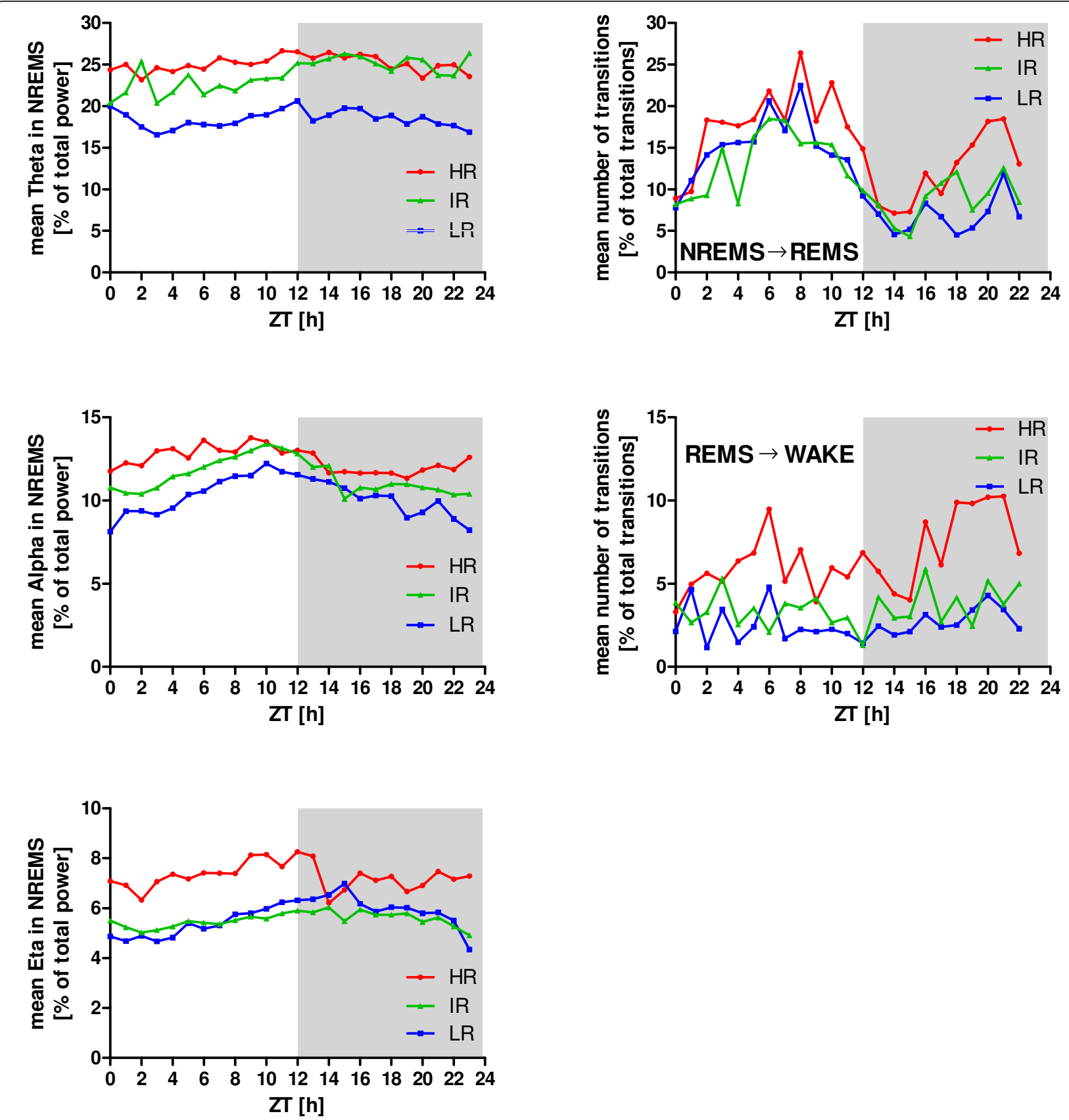

Figure 4 Stability of progressions over time in HR, IR and LR mice. Left column: The curve progressions of group means of normalized power (expressed in percent of the total power) are plotted separately for each breeding line during L1, L2, D1 and D2. The mean theta power and mean alpha power of the LR animals clearly showed a stable progression significantly below the mean of both frequency bands in HR and IR mice across the whole experimental time period. Right column: The number of transitions from NREMS to REMS and from REMS to WAKE in HR mice are significantly and robust above the transitions of IR and LR animals. Data are given as means without SEM for reasons of clarity.

The present analysis of the sleep/wake behavior in the SR model (Figure 1) revealed significant differences between the three breeding lines, especially increased amounts of REMS for the HR line during the resting period and the second half of the active period. For HR mice increased GC concentrations during the entire light period as well as at the end of the dark period were shown [37], pointing towards an increased HPA axis activity. It was shown in several studies that $\mathrm{CRH}$, one major player of the HPA axis, can promote REMS. In rats, for example, it was stated that after sleep deprivation with the water-tank method, $\mathrm{CRH}$ mediating 


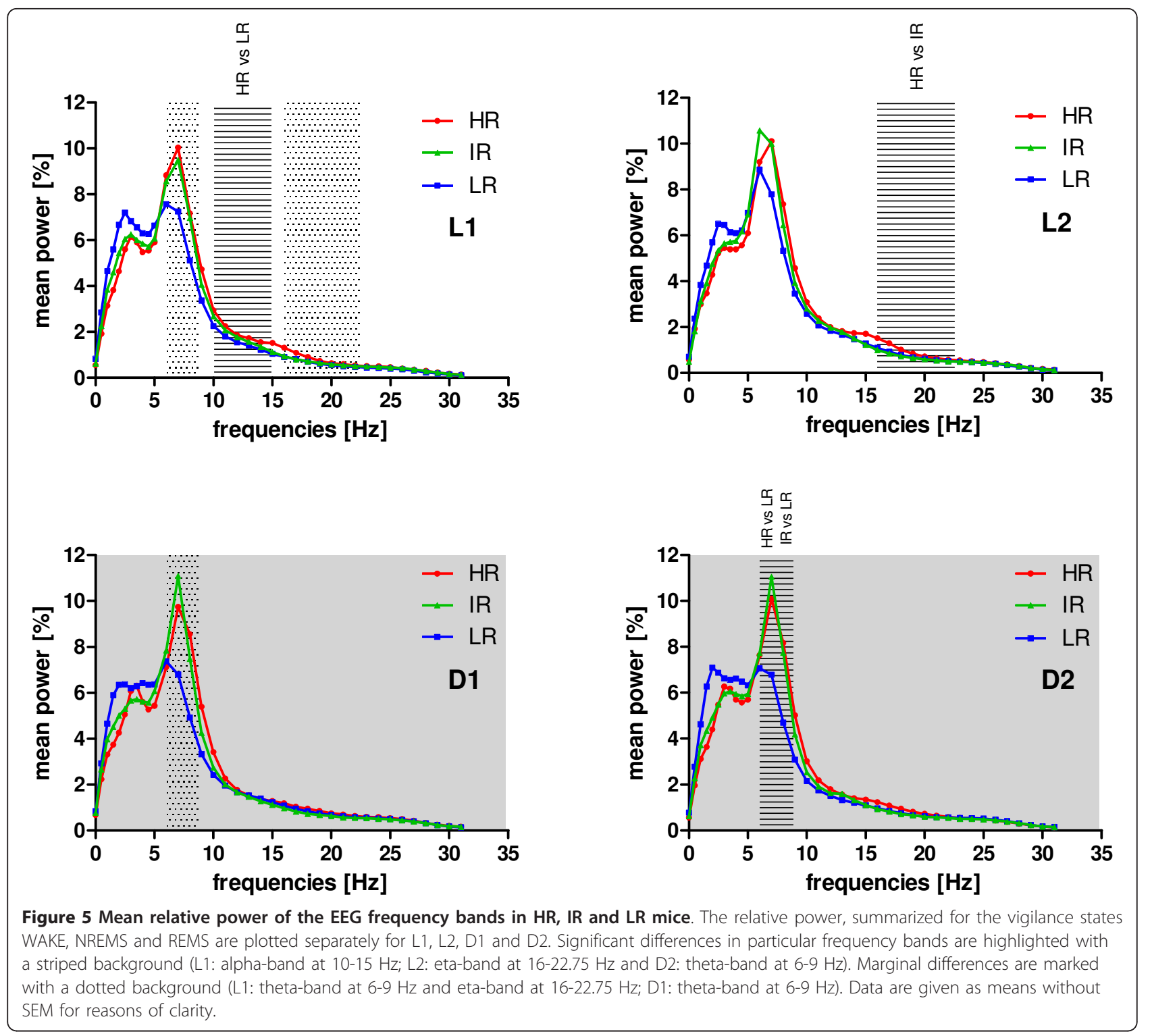

stress could be the main factor inducing a REMS rebound [41] and suppression of slow wave sleep (SWS) $[42,43]$. In mice, which conditionally and CNS-restricted over-express $\mathrm{CRH}$, enhanced REMS was attributed to an enhanced CRH secretion [44]. These authors also stated that elevated REMS may serve as a premorbid precursor of hypersecreted $\mathrm{CRH}$ predicting a clinical condition such as depression. Similar findings were reported in clinical studies, where the disinhibition of REMS during depression was assigned to a synergism of elevated $\mathrm{CRH}$ and cortisol activity [45]. Interestingly, $\mathrm{CRH}$ and $\mathrm{CRH}$ receptor type 1 and 2 agonists are able to either decrease [46-48] or increase [49] the amount of REMS in both rats and mice. It was concluded that the fragile vigilance state of REMS may be influenced by $\mathrm{CRH}$ in opposite directions, depending on the experimental design [46]. Our data from HR mice with a hyperreactive HPA axis also support the notion that elevated REMS is a sign of increased activity of the CRH system.

Increased secretion of $\mathrm{CRH}$ in HR animals may also contribute to increased levels of wakefulness in HR animals during the second half of the light period. In rats, restraint stress during the light period resulted in prolonged wakefulness, while $\mathrm{CRH}$ receptor antagonists blocked the increase in waking [50]. The reduction of physiologically active CRH levels through application of $\mathrm{CRH}$ antisense oligodeoxynucleotides under stress-free conditions led to a reduction in wakefulness, and it was concluded that $\mathrm{CRH}$ is involved also in the modulation of spontaneous awaking [51].

The increased amount of REMS in HR mice could not simply be attributed to more REMS per se, as a 
comparison of the mean REMS episode length revealed no significant differences in all four experimental time periods L1-D2 (Figure 3). Rather, the HR line had an increased transition frequency into REMS (from NREMS, although only significant during D2) and from REMS towards wakefulness (Figure 2). These differences in sleep architecture may be partly due to REMS promoting effects of $\mathrm{CRH}$, as discussed above. Accordingly, CRH does not act on duration of REMS episodes but on their amount, leading to an instable and fragmented balance between REMS and wakefulness (Figure 2). Similar sleep alterations were found in a different mouse model of depression. Mice selectively bred for high spontaneous helplessness in the tail suspension test showed enhanced REMS pressure and fragmented sleep [52]. Hyperactivity of the HPA axis, which is observed in depressed patients $[53,54]$, may have been responsible for these physiological changes in sleep/wake behavior, as the helpless mice had elevated serum corticosterone levels [52]. In humans, a causal coherence between impaired sleep and HPA axis hyperactivity was also suggested in the melancholic subtype of depression $[45,55]$.

The increased number of transitions from NREMS to REMS and especially from REMS towards wakefulness in HR animals were consistently above the number of transitions in IR and LR mice across the entire recording time (Figure 4). This points towards a robust phenotype within the sleep architecture of HR animals supporting the applicability of the SR mouse model to mimic sleep impairments in depression such as fragmented sleep.

\section{Theta enhancement in HR mice}

The theta frequency $(6-12 \mathrm{~Hz}$, according to different authors) represents the dominant oscillation during REMS [56-59]. It strongly depends on inhibitory GABAergic and excitatory acetylcholinergic inputs from the medial septum into the hippocampus $[56,60]$. It has been shown that $\mathrm{CRH}$ can modulate cholinergically driven hippocampal theta frequency [61] or even enhance theta amplitude and frequency [62]. Interestingly, although the cholinergic and the $\mathrm{CRH}$ system seem to interact, $\mathrm{CRH}$ enhanced pharmacologically induced cholinergic blockades, leading to impairments during spatial learning [63]. Increased amounts of CRH may, on the one hand, be responsible for enhanced theta activity in HR animals, compared to LR mice (Figure 5), probably causing deficits of HR animals in object memory and spatial memory tasks [38]. Partly not in accordance with this are findings that, although IR animals had increased theta activity, compared to LR mice but not to HR animals (Figure 5), this breeding line did show only intermediate levels of corticosterone when all three lines (HR vs. IR vs. LR) were compared [35] and spatial memory performance in IR was not as affected as in HR mice [38]. Although it is well established that patients with major depression show cognitive impairments [64,65], such symptoms often outlast a recovery from psychopathological symptoms and it seems unlikely that solely hypercortisolism causes these disabilities [66]. It will need to be clarified, in how far cognitive impairments are due to hypercortisolemia-induced long-term changes in relevant brain regions such as the hippocampus [66]. In general, the above outlined interpretation of our data must be critically evaluated in future experiments, since theta enhancement in HR mice may have also been partly caused simply by increased amounts of wakefulness (Figure 1, L2) and REMS (Figure 1, L1, L2 and D2).

\section{Differentiated alpha frequencies}

Cortico-cortical and thalamo-cortical circuits were thought to provide neuronal origins of oscillatory EEG alpha activity $[67,68]$. More recent publications attribute the alpha band to interconnected populations of layer $\mathrm{V}$ neurons from the occipital cortex [69].Modulation of these generators may be realized at the thalamic level, induced by the reticular activating system within the brainstem [70]. The locus coeruleus (LC), as part of the reticular activating system projects to the thalamus (additionally to the forebrain, cortex and hypothalamus) and activation through CRH leads to an increase in EEG frequency, decreased SWS $(0.5-4.5 \mathrm{~Hz})$ and increased wakefulness [71,72].Interestingly, LC neurons also discharge maximally during stressful conditions through local release of CRH [73-75].

Increased alpha bands were not only present in HR animals during the first half of the light period, but also in humans in conjunction with depression [76]. These authors classified participants in their study in a high vs. low depression group, according to their scores on two different inventories and found that high depression participants had more alpha activity $(8-13 \mathrm{~Hz})$ in frontal and parietal regions of the EEG. As predicted for depression, when differentiating between the two hemispheres of the cortex, less right frontal alpha activity was associated with better memory performance in the low depression group [76] (for the relationship between hemispheric EEG-asymmetry and different aspects of emotion, refer to e.g. [77]). Increased alpha activity in HR animals, when compared with LR animals may also contribute to memory deficits found in HR mice, thus supporting the notion that the SR model is a promising animal model for cognitive deficits in depression [36,38].

\section{Increased eta power in HR mice}

Moreover, we found that HR animals had increased eta power $(16-22.75 \mathrm{~Hz})$ during the second half of the light period. The eta band as investigated in our study 
represents a section of the frequency range normally described as beta band in literature (beta can range from $12 \mathrm{~Hz}$ to $35 \mathrm{~Hz}$, depending on individual settings of the experimenter and the species under investigation). Historically, the beta band was set at $12-30 \mathrm{~Hz}$ [78]. We introduced the eta band in earlier studies to specify the delta and the beta band during data analysis according to the species-specific EEG of mice (for a precise description of the algorithm, refer to [79]), as opposed to the suggested specifications for rats [80]. The narrow specification of our eta band is hardly found in the literature, when oscillations are discussed; thus, every conclusion from our data on increased eta power would be speculative. Interestingly enough, in humans faster frequencies (the authors defined beta as $14.75-30 \mathrm{~Hz}$ ) were stated to be indicative of cortical arousal [81], supporting the CNS hyperarousal hypothesis for insomnia [82,83], and beta- 2 oscillations (20-30 Hz, as stated by the authors), recorded from the somatosensory and motor cortices were coherent with muscle electrical activity [81]. Our data on increased eta activity (as part of beta) during L2 in HR mice (Figure 5) may be linked to the increased wakefulness detected during L2 (Figure 1).

\section{Stability of data across recordings}

The robustness of the above described theta, alpha and eta differences were predominantly found during NREMS with high stability across the whole recording time (Figure 4), whereas no robust differences for these frequency bands could be observed during REMS (data not shown). It is tempting to speculate that HR mice with robustly increased alpha and eta power, although not dramatically more awake than IR and LR mice during L1-D2 have a shallower NREMS. This is in accordance with clinical studies describing shallow sleep in depressed patients $[45,84]$. The stability in the progression of increased theta power in HR mice across the whole recording period (Figure 4) could, at least partly, explain the increased amounts of REMS during L1, L2 and D2, also mirrored in the increased transition frequencies from REMS to wakefulness in L2, D1 and D2. In contrary to increased theta, over time robustly reduced amounts of this frequency band, as detected in LR animals may serve as a driving force to decrease REMS.

In general, the beta and delta bands are very much parallel among humans and primates, but one has to be very critical in transferring findings from a rodent EEG to a human EEG, especially for the alpha and theta bands.

\section{Conclusions}

HR mice, i.e. those animals that have a genetic predisposition for hyper-activating their HPA axis in response to restraint stress, showed altered sleep architecture, similar to what is known from depressed patients. Moreover, robust differences along the activities of several frequency bands of the EEG, which also seem to at least partly mimic clinical observations, suggest the stressreactivity mouse model understanding the mechanisms underlying sleep impairments in patients suffering from stress-related diseases. The herein reported findings also underscore the notion that sleep-EEG measures in rodents could help to find human biomarkers in the future which might provide tools to create patient subgroups with similar, if not identical disease mechanisms.

\section{Methods}

Animals and housing conditions

All animals used in this study derived from the seventh generation (Gen VII) of the 'stress reactivity' (SR) mouse model [35]. This model was generated from the CD-1 mouse strain and consists of three independent mouse lines selectively bred for either high (HR), intermediate (IR) or low (LR) reactivity of the HPA axis (for a detailed description see [35]. Eight adult males of each breeding line (HR, LR and IR) were used in the experiment. Each animal was housed separately in an individual recording cage located in a sound attenuated chamber at constant laboratory conditions $\left(23 \pm 1^{\circ} \mathrm{C}\right.$, 12-12 h light-dark cycles, lights on: $10 \mathrm{am})$. Food and water were available ad libitum.

\section{Surgery}

An isofluran/oxygen anesthesia (custom made vaporizing device) was used during all surgical preparations of the animals. Prior to the surgery, each animal received atropine sulfate $(0.05 \mathrm{mg} / \mathrm{kg} \mathrm{BW})$ and meloxicam $(0.5 \mathrm{mg} / \mathrm{kg}$ BW) subcutaneously. Each animal was surgically equipped with four epidural electroencephalogram (EEG) and two intramuscular electromyogram (EMG) electrodes. A detailed description of the surgeral procedure is described elsewhere $[37,79]$. Briefly, to place the EEG electrodes on the cortex, four small holes were drilled into the skull preserving the cerebral membrane. Two electrodes were bilaterally placed at the standard frontal region of the skull (caudal third of os frontalis), one reference-electrode was placed at the right standard parietal area and the ground electrode was inserted at the left standard parietal area (center of os parietalis). Both frontal electrodes where referenced to the right parietal electrode. The contrallateral lead was analyzed, the ipsilateral lead only served as additional recording track, if the standard lead could not be analyzed. Two EMG electrodes were embedded bilaterally of the spine into the neck muscles. Postoperative the animals received meloxicam added to the drinking water $(0.5 \mathrm{mg} / \mathrm{kg} \mathrm{BW})$. After surgery, the animals were allowed to recover for two weeks 
in individual recording cages with recording cables attached to them before two successive 23 hour recording sessions of EEG and EMG signals were performed. Each recording cable was connected to a swivel system allowing free movements of the animal.

\section{Data processing}

EEG and EMG signals were fed online into a differential preamplifier (1000x, custom made) and main amplifier (10x, custom made). The EEG signals were analog bandpass filtered $(0.5-29 \mathrm{~Hz}$, filter frequency roll off 48 $\mathrm{dB}$ /octave) and digitized with a sampling rate of $64 \mathrm{~Hz}$ (AD board, NI PCI-6070, National Instruments, Austin, USA). Root mean square was applied to all non-filtered EMG signals before its digital conversion (sample rate: $64 \mathrm{~Hz}$ ). Fast Fourier transform (FFT) for the spectral analysis was applied on consecutive 4 sec intervals. The vigilance states WAKE, NREMS and REMS in each of these intervals were pre-scored semi-automatically with a LabVIEW-based sleep scoring program (SEA, Koeln, Germany) and were rescored manually. The frequency bands applied to the semi-automatic scoring algorhythm and for statistical quantifications were as follows: delta: $0.75-5 \mathrm{~Hz}$; theta: $6.0-9.0 \mathrm{~Hz}$; alpha: $10.0-15.0 \mathrm{~Hz}$; eta: 16.0-22.75 Hz; beta: 23.0-31.75 Hz. The applied scoring algorhythm was originally based on experiments with rats [80]; the eta band was additionally specified in our experiments [79] to meet the criteria for the slightly different mouse EEG. A detailed description of the scoring procedure is described elsewhere [79].

\section{Statistical analysis}

In general, statistical evaluations and the corresponding graphs refer to four separate time intervals of the total recording time: L1 (first half of the light period: ZT0-6 [h]); L2 (second half of the light period: ZT6-12 [h]); D1 (first half of the dark period: ZT12-18 [h]) and D2 (second half of the dark period: ZT18-23 [h]). Of primary interest was the investigation of group effects on the relative stay in the three different vigilance states (WAKE, NREMS, REMS) as well as on the relative transition frequencies between the vigilance states within each of the mentioned time intervals (Note: the relative stays in WAKE, NREM or REMS refers to the total stay, which is equal to the length of the considered time interval and the relative transitions refers to the total transitions within the corresponding time intervals. Such relative quantities are often called normed quantities). Group effects on the normed durations of individual vigilance states and normed transition frequencies were statistically analysed by multivariate analyses of variance (MANOVAs) for each time interval separately. In cases of significant main (global) group effects, univariate $\mathrm{F}$ tests followed to identify those variables on which the group effect was significant. For these variables post-hoc tests (Bonferroni modified LSD tests) were subsequently applied for investigating the significance of contrasts or simple effects i.e. of the differences between group pairs in the variables showing main group effects. Group comparisons of the mean REMS episode length were performed individually for L1-D2 by means of one-way analyses of variance. For evaluating group differences in the power of the known frequency bands (delta, theta, alpha, eta, beta) determining in each of the vigilance states the area under the curve (AUC) in each time interval using the trapezoid rule was first calculated and then analyses of variance were performed.

Finally the assumption that for particular groups the frequency bands across the experimental time lie constantly over those of other groups (known as stability hypothesis [85]) was tested for significance with a Wilcoxon Matched-Pairs Signed-Ranks test by considering the part of each mean power above the common median at each time point (ZT1-ZT23). The nominal level of significance was accepted with $\mathrm{p}<0.05$. To keep the type I error less or equal to 0.05 , all posteriori tests (univariate $\mathrm{F}$ tests, tests with contrasts) were performed with reduced levels of significance (adjusted $\alpha$ according to the Bonferroni procedure). All data are expressed as mean \pm SEM.

\section{Animal care}

Laboratory animal care and all experimental procedures were conducted in accordance with the regulations of the current German Animal Protection Act. The protocols were approved by the Government of Bavaria (AZ209.1/211-33/04 and AZ55.2/1/54-2531-64/07).

\section{Author details}

${ }^{1}$ Max-Planck-Institute of Psychiatry, Kraepelinstrasse 2, 80804 Munich, Germany. ${ }^{2}$ Max-Planck-Institute of Neurobiology, Am Klopferspitz 18, 82152 Martinsried, Germany.

\section{Authors' contributions}

Conceived and designed the study: TF CT AY. Performed the experiments: FT CT JR CPNR. Analyzed the data: TF CT AY. Reviewed the manuscript: HF RL CPNR MK. Wrote the paper: TF CT AY. All authors read and approved the final manuscript.

Received: 14 October 2010 Accepted: 24 March 2011

Published: 24 March 2011

\section{References}

1. Hastings $M H$, Reddy $A B$, Maywood ES: A clockwork web: circadian timing in brain and periphery, in health and disease. Nat Rev Neurosci 2003, 4:649-661.

2. Takahashi JS, Hong HK, Ko CH, McDearmon EL: The genetics of mammalian circadian order and disorder: implications for physiology and disease. Nat Rev Genet 2008, 9:764-775.

3. Devlin PF, Kay SA: Circadian photoperception. Annu Rev Physiol 2001, 63:677-694.

4. de Kloet ER, Joels M, Holsboer F: Stress and the brain: from adaptation to disease. Nat Rev Neurosci 2005, 6:463-475. 
5. Von Holst D: The Concept of Stress and Its Relevance for Animal Behavior. Adv Study Behav 1998, 27:1-131.

6. Holsboer F, Ising M: Stress Hormone Regulation: Biological Role and Translation into Therapy. Annu Rev of Psychol 2010, 61:81-109.

7. Korte SM, Koolhaas JM, Wingfield JC, McEwen BS: The Darwinian concept of stress: benefits of allostasis and costs of allostatic load and the tradeoffs in health and disease. Neurosci Biobehav Rev 2005, 29:3-38.

8. Sapolsky RM, Romero LM, Munck AU: How Do Glucocorticoids Influence Stress Responses? Integrating Permissive, Suppressive, Stimulatory, and Preparative Actions. Endocr Rev 2000, 21:55-89.

9. Nader N, Chrousos GP, Kino T: Interactions of the circadian CLOCK system and the HPA axis. Trends Endocrin Met 2010, 21:277-286.

10. Steiger A: Neurochemical regulation of sleep. J Psychiat Res 2007, 41:537-552.

11. Kriegsfeld $L$, Silver $R$ : The regulation of neuroendocrine function: Timing is everything. Horm Behav 2006, 49:557-574.

12. Steiger A, Kimura M: Wake and sleep EEG provide biomarkers in depression. J Psychiat Res 2010, 44:242-252.

13. Antonijevic I: HPA axis and sleep: Identifying subtypes of major depression. Stress 2008, 11:15-27.

14. Steiger A: Sleep and the hypothalamo-pituitary-adrenocortical system. Sleep Med Rev 2002, 6:125-138.

15. Modell S, Lauer CJ: Rapid eye movement (REM) sleep: an endophenotype for depression. Curr Psychiatry Rep 2007, 9:480-485.

16. Germain A, Kupfer DJ: Circadian rhythm disturbances in depression. Hum Psychopharmacol 2008

17. Holsboer F: The Corticosteroid Receptor Hypothesis of Depression. Neuropsychopharmacol 2000, 23:477-501.

18. Lauer CJ, Riemann D, Wiegand M, Berger M: From early to late adulthood changes in EEG sleep of depressed patients and healthy volunteers. Biol Psychiat 1991, 29:979-993.

19. Steiger A, von Bardeleben U, Herth T, Holsboer F: Sleep-EEG and nocturnal secretion of cortisol and human growth hormone in male patients with endogenous depression before treatment and after recovery. J Affect Disord 1989, 16:189-195.

20. Rush AJ, Erman MK, Giles DE, Schlesser MA, Carpenter G, Vasavada N, et al Polysomnographic findings in recently drug-free and clinically remitted depressed patients. Arch Gen Psychiatry 1986, 43:878-884.

21. Giles DE, Jarrett RB, Roffwarg HP, Rush AJ: Reduced rapid eye movement latency: A predictor of recurrence in depression. Neuropsychopharmacol 1987, 1:33-39.

22. Gottesmann C, Gottesman I: The neurobiological characteristics of rapid eye movement (REM) sleep are candidate endophenotypes of depression, schizophrenia, mental retardation and dementia. Prog in Neurobiol 2007, 81:237-250

23. Modell S, Ising M, Holsboer F, Lauer CJ: The Munich Vulnerability Study on Affective Disorders: Premorbid Polysomnographic Profile of Affected High-Risk Probands. Biological Psychiatry 2005, 58:694-699.

24. Thomson F, Craighead M: Innovative approaches for the treatment of depression: targeting the HPA axis. Neurochem Res 2008, 33:691-707.

25. Hasler G, Drevets WC, Manji HK, Charney DS: Discovering endophenotypes for major depression. Neuropsychopharmacol 2004, 29:1765-1781.

26. Gold PW, Chrousos GP: Organization of the stress system and its dysregulation in melancholic and atypical depression: high vs low CRH/ NE states. Mol Psychiat 2002, 7:254-275.

27. Nestler EJ, Barrot M, DiLeone RJ, Eisch AJ, Gold SJ, Monteggia LM: Neurobiology of Depression. Neuron 2002, 34:13-25.

28. Wong ML, Kling MA, Munson PJ, Listwak S, Licinio J, Prolo P, et al: Pronounced and sustained central hypernoradrenergic function in major depression with melancholic features: relation to hypercortisolism and corticotropin-releasing hormone. Proc Natl Acad Sci USA 2000, 97:325-330.

29. Keller J, Flores B, Gomez RG, Solvason HB, Kenna H, Williams GH, et al: Cortisol circadian rhythm alterations in psychotic major depression. Biol Psychiat 2006, 60:275-281.

30. Deuschle M, Schweiger U, Weber B, Gotthardt U, Korner A, Schmider J, et al: Diurnal activity and pulsatility of the hypothalamus-pituitaryadrenal system in male depressed patients and healthy controls. J Clin Endocrinol Metab 1997, 82:234-238.

31. Sachar EJ, Hellman L, Roffwarg HP, Halpern FS, Fukushima DK, Gallagher TF: Disrupted 24-Hour Patterns of Cortisol Secretion in Psychotic Depression. Arch Gen Psychiat 1973, 28:19-24.
32. Angst J, Gamma A, Sellaro R, Zhang H, Merikangas K: Toward validation of atypical depression in the community: results of the Zurich cohort study. J Affect Disord 2002, 72:125-138.

33. Antonijevic IA: Depressive disorders - is it time to endorse different pathophysiologies? Psychoneuroendocrinol 2006, 31:1-15.

34. Bale TL: Stress sensitivity and the development of affective disorders. Horm Behav 2006, 50:529-533.

35. Touma C, Bunck M, Glasl L, Nussbaumer M, Palme R, Stein H, et al: Mice selected for high versus low stress reactivity: a new animal model for affective disorders. Psychoneuroendocrinol 2008, 33:839-862.

36. Knapman A, Heinzmann JM, Holsboer F, Landgraf R, Touma C: Modeling psychotic and cognitive symptoms of affective disorders: Disrupted latent inhibition and reversal learning deficits in highly stress reactive mice. Neurobiol Learn \& Mem 2010, 94:145-152.

37. Touma C, Fenzl T, Ruschel J, Palme R, Holsboer F, Kimura M, et al: Rhythmicity in Mice Selected for Extremes in Stress Reactivity: Behavioural, Endocrine and Sleep Changes Resembling Endophenotypes of Major Depression. PLOS ONE 2009, 4:e4325.

38. Knapman A, Heinzmann JM, Hellweg R, Holsboer F, Landgraf R, Touma C: Increased stress reactivity is associated with cognitive deficits and decreased hippocampal brain-derived neurotrophic factor in a mouse model of affective disorders. J Psychiat Res 2010, 44:566-575.

39. Yassouridis A, Steiger A, Klinger A, Fahrmeir L: Modelling and exploring human sleep with event history analysis. J Sleep Res 1999, 8:25-36

40. Van Twyver H: Sleep patterns of five rodent species. Physiol Beh 1969, 4:901-905.

41. Gonzalez MM, Valatx JL: Involvement of stress in the sleep rebound mechanism induced by sleep deprivation in the rat: use of alpha-helical CRH (9-41). Behav Pharmacol 1998, 9:655-662.

42. Holsboer F, von Bardeleben U, Steiger A: Effects of intravenous corticotropin-releasing hormone upon sleep-related growth hormone surge and sleep EEG in man. Neuroendocrinol 1988, 48:32-38.

43. Ehlers $C L$, Reed TK, Henriksen SJ: Effects of corticotropin-releasing factor and growth hormone-releasing factor on sleep and activity in rats. Neuroendocrinol 1986, 42:467-474

44. Kimura M, Muller-Preuss P, Lu A, Wiesner E, Flachskamm C, Wurst W, et al: Conditional corticotropin-releasing hormone overexpression in the mouse forebrain enhances rapid eye movement sleep. Mol Psychiat 2010, 15:154-165.

45. Steiger A: Sleep and the hypothalamo-pituitary-adrenocortical system. Sleep Med Rev 2002, 6:125-138.

46. Romanowski CP, Fenzl T, Flachskamm C, Wurst W, Holsboer F, Deussing JM, et al: Central deficiency of corticotropin-releasing hormone receptor type 1 (CRH-R1) abolishes effects of CRH on NREM but not on REM sleep in mice. Sleep 2010, 33:427-436.

47. Pawlyk AC, Sanford LD, Brennan FX, Morrison AR, Ross RJ: Corticotropinreleasing factor microinjection into the central nucleus of the amygdala alters REM sleep. Pharmacol Rep 2006, 58:125-130.

48. Yang L, Tang X, Wellman LL, Liu X, Sanford LD: Corticotropin releasing factor (CRF) modulates fear-induced alterations in sleep in mice. Brain Res 2009, 1276:112-122.

49. Wellman LL, Yang L, Rodriguez CC, Dong E, Tang X, Sanford LD: CRF1 but not $C R F 2$ receptors in the central nucleus of the amygdala (CNA) regulate rapid eye movements sleep (REM) in rats. Sleep 32, A7 2009.

50. Chang FC, Opp MR: Role of corticotropin-releasing hormone in stressorinduced alterations of sleep in rat. Am J Physiol Regul Integr Comp Physiol 2002, 283:R400-R407.

51. Chang FC, Opp MR: A corticotropin-releasing hormone antisense oligodeoxynucleotide reduces spontaneous waking in the rat. Regul Pept 2004, 117:43-52.

52. El Yacoubi M, Bouali S, Popa D, Naudon L, Leroux-Nicollet I, Hamon M, et al: Behavioral, neurochemical, and electrophysiological characterization of a genetic mouse model of depression. Proc Natl Acad Sci USA 2003, 100:6227-6232

53. Reul JMHM, Holsboer F: Corticotropin-releasing factor receptors 1 and 2 in anxiety and depression. Curr Opin Pharmacol 2002, 2:23-33.

54. Arborelius L, Owens MJ, Plotsky PM, Nemeroff CB: The role of corticotropin-releasing factor in depression and anxiety disorders. J Endocrinol 1999, 160:1-12.

55. Antonijevic I: HPA axis and sleep: Identifying subtypes of major depression. Stress 2007, 1-13. 
56. Kahana MJ, Seelig D, Madsen JR: Theta returns. Curr Opin Neurobiol 2001, 11:739-744.

57. Louie K, Wilson MA: Temporally structured replay of awake hippocampal ensemble activity during rapid eye movement sleep. Neuron 2001, 29:145-156.

58. Jouvet M: Biogenic amines and the states of sleep. Science 1969, 163:32-41

59. Buzsaki G, Buhl DL, Harris KD, Csicsvari J, Czéh B, Morozov A: Hippocampal network patterns of activity in the mouse. Neurosci 2003, 116:201-211.

60. Hasselmo ME, Hay J, llyn M, Gorchetchnikov A: Neuromodulation, theta rhythm and rat spatial navigation. Neural Netw 2002, 15:689-707.

61. Kortekaas R, Costall B, Smythe JW: Changes in hippocampal theta following intrahippocampal corticotropin-releasing hormone (CRH) infusions in the rat. Brain Res Bull 1999, 48:603-607.

62. Pieretti S, Ortolani E, Di Giannuario A, Loizzo A: Effects of endorphin derivatives on the EEG alterations induced by corticotropin releasing factor in the rabbit hippocampus. Pharmacol Res 1990, 22:627-633.

63. Steckler T, Holsboer F: Interaction between the cholinergic system and $\mathrm{CRH}$ in the modulation of spatial discrimination learning in mice. Brain Res 2001, 906:46-59.

64. Reppermund S, Ising M, Lucae S, Zihl J: Cognitive impairment in unipolar depression is persistent and non-specific: further evidence for the final common pathway disorder hypothesis. Psychol Med 2009, 39:603-614.

65. Bearden CE, Glahn DC, Monkul ES, Barrett J, Najt P, Villarreal V, et al: Patterns of memory impairment in bipolar disorder and unipolar major depression. Psychiat Res 2006, 142:139-150.

66. Reppermund S, Zihl J, Lucae S, Horstmann S, Kloiber S, Holsboer F, et al Persistent cognitive impairment in depression: the role of psychopathology and altered hypothalamic-pituitary-adrenocortical (HPA) system regulation. Biol Psychiat 2007, 62:400-406.

67. Kubie LS: A theoretical application to some neurological problems of the properties of sxcitation waves which move in close circuits. Brain 1930, 53:166-177.

68. Lorente de No R: Studies of the structure of the cerebral cortex. J Psychol U Neurol 1933, 45:438.

69. Silva LR, Amitai Y, Connors BW: Intrinsic oscillations of neocortex generated by layer 5 pyramidal neurons. Science 1991, 251:432-435.

70. Cantero JL, Atienza M, Salas RM: Human alpha oscillations in wakefulness, drowsiness period, and REM sleep: different electroencephalographic phenomena within the alpha band. Neurophysiol Clin 2002, 32:54-71.

71. Nolte J: Organization of the brainstem. The human brain St. Louis: Mosby; 2002, 262-290.

72. Buckley TM, Schatzberg AF: On the Interactions of the HypothalamicPituitary-Adrenal (HPA) Axis and Sleep: Normal HPA Axis Activity and Circadian Rhythm, Exemplary Sleep Disorders. J Clin Endocrinol Metab 2005, 90:3106-3114.

73. Aston-Jones G, Rajkowski J, Kubiak P, Valentino RJ, Shipley MT: Role of the locus coeruleus in emotional activation. Prog Brain Res 1996, 107:379-402.

74. Valentino RJ, Page ME, Curtis AL: Activation of noradrenergic locus coeruleus neurons by hemodynamic stress is due to local release of corticotropin-releasing factor. Brain Res 1991, 555:25-34.

75. Curtis AL, Lechner SM, Pavcovich LA, Valentino RJ: Activation of the Locus Coeruleus Noradrenergic System by Intracoerulear Microinfusion of Corticotropin-Releasing Factor: Effects on Discharge Rate, Cortical Norepinephrine Levels and Cortical Electroencephalographic Activity. J Pharmacol Exp Ther 1997, 281:163-172.

76. Nitschke JB, Heller W, Etienne MA, Miller GA: Prefrontal cortex activity differentiates processes affecting memory in depression. Biol Psychol 2004, 67:125-143.

77. Allen JJB, Kline JP: Frontal EEG asymmetry, emotion, and psychopathology: the first, and the next 25 years. Biol Psychol 2004, 67:1-5.

78. Buzsaki G: A System of Rhythms: From simple to complex dynamics. Rhythms of the Brain Oxford: University Press; 2006, 111-135.

79. Fenzl T, Romanowski CP, Flachskamm C, Honsberg K, Boll E, Hoehne A, et al: Fully automated sleep deprivation in mice as a tool in sleep research. J Neurosci Methods 2007, 166:229-235.

80. Louis RP, Lee J, Stephenson R: Design and validation of a computerbased sleep-scoring algorithm. J Neurosci Methods 2004, 133:71-80.

81. Merica H, Blois R, Gaillard JM: Spectral characteristics of sleep EEG in chronic insomnia. Eur J Neurosci 1998, 10:1826-1834
82. Bonnet MH, Arand DL: The consequences of a week of insomnia. Sleep 1996, 19:453-461.

83. Bonnet $\mathrm{MH}$, Arand DL: 24-Hour metabolic rate in insomniacs and matched normal sleepers. Sleep 1995, 18:581-588.

84. Friess E, Wiedemann K, Steiger A, Holsboer F: The hypothalamic-pituitaryadrenocortical system and sleep in man. Adv Neuroimmunol 1995, 5:111-125

85. Wiedemann K, Jahn H, Yassouridis A, Kellner M: Anxiolyticlike effects of atrial natriuretic peptide on cholecystokinin tetrapeptide-induced panic attacks: preliminary findings. Arch Gen Psychiat 2001, 58:371-377.

doi:10.1186/1471-2202-12-29

Cite this article as: Fenzl et al: Sleep disturbances in highly stress reactive mice: Modeling endophenotypes of major depression. BMC Neuroscience 2011 12:29.

\section{Submit your next manuscript to BioMed Central and take full advantage of:}

- Convenient online submission

- Thorough peer review

- No space constraints or color figure charges

- Immediate publication on acceptance

- Inclusion in PubMed, CAS, Scopus and Google Scholar

- Research which is freely available for redistribution
Ciomed Central 